Article

\title{
Towards Sustainable Cities: Extending Resilience with Insights from Vulnerability and Transition Theory
}

\section{Leanne Seeliger * and Ivan Turok}

Human Sciences Research Council, Economic Performance and Development; Private Bag X9182, Cape Town 8000, South Africa; E-Mail: iturok@hsrc.ac.za

* Author to whom correspondence should be addressed; E-Mail: 1seeliger@hsrc.ac.za; Tel.: +27-21-466-7924; Fax: +27-21-466-8001.

Received: 1 March 2013; in revised form: 6 May 2013 / Accepted: 7 May 2013 /

Published: 8 May 2013

\begin{abstract}
Cities at all stages of development need to provide jobs, food and services for their people. There is no formula that can unilaterally be applied in all urban environments to achieve this. The complex interaction of social, economic and ecological cycles within cities makes it impossible to predict outcomes. Resilience theory, with its engineering, multi-equilibria and socio-ecological approaches, provides some of the foundations for understanding the full range of the complex social and ecological interactions that underpin sustainable cities. It is proposed that these insights could be extended by a sharper focus on the social and technological innovation that has traditionally been the emphasis of vulnerability and transition theories respectively.
\end{abstract}

Keywords: resilience; vulnerability; transition; socio-ecological system; adaptability; transformation; sustainable cities

\section{Introduction}

Cities at all stages of development are exposed to increasing economic and environmental pressures and instabilities associated with globalization, urbanization, climate change and resource depletion. A United Nations study in 2011 found that 60 percent of the people living in the world's 450 largest cities were at a high risk of exposure to at least one natural hazard [1]. Most of these are in South-East Asia, with a few in North and South America, and surprisingly few in Europe and Africa. The specific nature of these shocks and stresses are varied ranging from cyclones, flooding to drought and 
landslides. The top five mega-cities at high risk to one hazard are Tokyo, Delhi, Mexico City, New York and Shanghai.

These hazards are often difficult to anticipate and may interact in ways that amplify their consequences. For example, in New York, where there is a medium risk of cyclones and high risk of floods, Hurricane Sandy left millions of residents without power, closed one of the world's main stock exchanges and cost tens of billions of dollars in property damage and lost business. Despite large parts of the city being inundated the basic infrastructure was soon restored, the economy rebounded, and health care and social security systems protected most households whose lives were temporarily disrupted. New York's ability to rebound so quickly was partly due to the city's capital resources as well as financial and social networks.

Not all cities would be able to recover this quickly. The global financial crisis has in many places ushered in a period of austerity, heightening the risks of adversity for urban citizens and governments, making it difficult for them to cope with these kinds of unexpected events. The capabilities of cities to cope with hazardous occurrences and adapt to unfavorable conditions is crucial to their prospects of sustained growth and development. The concept of resilience has become popular in referring to the essential attributes of cities that enable them to deal with disasters and other threats over which they have little control.

Africa, despite it falling outside the prime high risk zone for exposure to natural hazards, cannot afford to be complacent. Urban population growth is expected to be mostly a developing world phenomenon with the continent expecting a 0.9 billion increase in its population [1]. For example, Juba, the capital of the new Republic of Sudan is one of the fastest growing cities in human history, because of the large numbers of people displaced from the surrounding region by rural famine and civil conflict [2]. It is devoid of formal institutions and infrastructure and residents are in dire need of improved living standards and security. More than half of its population is living below the poverty line and public spending is dependent on foreign aid and intermittent oil revenues.

What makes cities robust and resourceful in the face of such diverse environmental, social and economic difficulties? Their ability to maintain vital functions while at the same time adapting and developing in the light of changing circumstances is crucial for successful urban performance into the future. Sandy is an example of an increasingly frequent extreme event that brought one of the world's most prosperous cities to a standstill, albeit temporarily because it was well prepared and protected. Juba lacks the resources to cope with unprecedented population growth that exposes it to overcrowding, misery and disease in the absence of essential services. This paper discusses some of the basic requirements for cities in different circumstances to respond effectively to both sudden and slower-moving disturbances. It draws on the frameworks of resilience, vulnerability and transition to identify some of the inherent attributes that cities require for sustained growth and development.

The concept of resilience has gained rapid acceptance as a way to describe key features of durable ecological, social and economic systems. It seeks to explain how such systems withstand, recover from and reorganize in response to turbulent conditions. There are three main interpretations of resilience, which shed light on different kinds of response to crises. They emphasize the need to 'bounce back', 'bounce forward' and evolve in dynamic situations. However, this paper argues that resilience could be further enhanced by a sharper focus on human vulnerability and innovation. We turn to theories of vulnerability and transition to show how they incorporate these aspects more fully. Vulnerability pays 
particular attention to the specific groups of people that are most susceptible to harmful effects. Transition theory draws attention to the role of technology in enabling change and development.

This paper draws on examples of small, medium and larger cities to illustrate the breadth and depth of the concept of resilience and its application. The focus in these examples is on how change, both rapid and incremental, affects the complex interactions within and between the ecological and social aspects of cities, highlighting specifically the economic dimension of the latter.

Engineering resilience cannot be applied only to well-resourced cities in advanced economies. Nor can one surmise that the transformation implied by socio-ecological resilience is limited to developing countries. The kind of resilience that is required depends on the nature of the change and its expected impact on a city's resources and people. Similarly, the type of resilience is not fixed to a particular kind of concern like environmental, social or ecological. There are times when multi-equilibria resilience is just as applicable to concerns about ecological limits as it is to concerns about market stability. The examples discussed in the paper are presented to show that the type of resilience required is always dependent on the time frame and the location of the issue at hand. Flexibility, stability and innovation might mean different things in different places but they are essential capabilities that are critical for building sustainable cities.

\section{Framing Resilience within the Social Sciences}

The concept of resilience came to prominence with the insights generated by Holling in the discipline of ecology during the 1960s and early 1970s [3]. It was originally used to describe the persistence of natural systems in the face of disturbances and their ability to renew and reorganize themselves [4,5]. It was a technical, ecological term and was used to describe whether a social or physical system was able to absorb and recover from a disturbance. There were no value judgments inherent in describing whether such systems could withstand shocks. It was essentially factual statements: either the system could or could not.

Now, with its greater application in social science, the concept of resilience is also being used normatively to suggest that the ability to recover and survive is a desirable feature. This must be treated with caution because it is important not to assume that sustaining a system is necessarily desirable, especially for social systems, since the existing state of the system may well not be the optimum or 'normal' condition. Greater dynamism and upheaval may improve many systems. Furthermore, there are diverse and often conflicting values within all social systems, so it has to be established whether one outcome is preferable to another, and not taken for granted that the existing situation should be maintained.

There is another reason for being aware of the normative application of the concept of resilience, particularly when considering the interaction between social and ecological systems in cities and other human constructs. Social systems are strongly influenced by human intentions and perceptions, which in turn are guided by different and competing interests. The physical environment of cities is manipulated for human use with particular objectives and functions in mind. They may be to sustain certain kinds of commercial activities, to meet basic household needs, or to support recreational, artistic and cultural functions. These value land and related resources in different ways that are not easily reconciled. Hence the specific vantage point and framing values of those in positions of power 
and influence over the built environment are all-important. Cities and other socio-ecological systems are not neutral, disinterested arrangements exposed to immutable external forces with inevitable outcomes. They are subject to human agency and socially constructed in a variety of ways that need to be unpacked and elucidated.

Resilience has varied meanings in different disciplines and therefore the interdisciplinary use of the term can create confusion [4]. In biophysical sciences, resilience is traditionally referred to as the biological ability to persist in environments, whereas in economics it is often understood as the economy's ability to return to a steady state, or equilibrium [6].

In this paper, resilience is used to describe the 'social', 'economic' and 'environmental' responses to change in cities and the interactions between them at various scales. The emphasis is on the type of resilience that exists or is sought. It does not restrict a particular type of resilience to a specific discipline. When engineering resilience is discussed for example, the emphasis is on how ecological, economic or social systems can return to a previous state. In multi-equilibria resilience, the focus is on adapting these systems to maintain stability. On the other hand, when socio-ecological resilience is being investigated the dynamic nature of resilience is emphasized. Resilience is therefore not limited to persistence or restoration in ecology but could include adaptation. Similarly, it is not restricted to the maintenance of equilibrium in economics but could entertain the structural transformation of the economy.

Ambiguity and vagueness can be minimized when using the concept in this interdisciplinary fashion by carefully specifying the term each time so that its scope and meaning are clear. The context in which it is being used also needs careful definition so that there is little doubt about what is being discussed.

One requirement is to define the geographical and temporal boundaries under discussion-what scale of territory is relevant and over what time period [4,7]. Just how resilient New Orleans was against Hurricane Katrina depends on how the area is defined, for example, whether the affluent suburbs on higher ground are included with the poorer, low-lying areas. Assessing New York's resilience to Sandy depends on whether one is judging its recovery in days, months or years. In practice, there are difficult judgments to be made in defining the relevant system and to avoid excluding critical elements without good reason.

Second, one needs to recognize that different challenges necessitate different approaches to measuring resilience [7]. A sudden shock that causes violent disruption by breaching a threshold is quite different to gradual and persistent pressure for change. Monitoring the resilience of an area hit by an extreme climatic event is very different to assessing the slower processes of economic or social restructuring. Both can have pervasive detrimental consequences. One is external and immediate, whereas the other is ongoing and more internalized. Juba may appear to be just about surviving the effects of rapid urbanization on a day-to-day basis by avoiding overt social disorder and unrest, but the risks of damaging human outcomes need to be judged over a period of years as pressures accumulate and the capacity of local systems to cope is tested to the limit.

Third, there is a useful distinction to be made between specific and general resilience [8,9]. Specific resilience refers to the response of a system to a particular kind of change. For example, it could refer to how a coastal city adapts to rising sea levels caused by global warming. General resilience refers to a system's capacity to respond to a range of risks and uncertainties. The relationship between specific and general resilience is significant because an increase in specific resilience can reduce general 
resilience if it constrains flexibility to cope with other changes [10], perhaps by narrowing the options available through tying it into a particular path. Fixed capital investment in roads and other resource-intensive infrastructure is a classic example for cities. This can limit their capacity to absorb rising energy prices and reconfigure how they function in response to growing resource scarcity and pressure to raise efficiency.

Besides the framing issue, there are two other considerations to take into account when translating resilience from a natural to a social context, namely determinism and power. First, the ecological sciences tend to be more deterministic than the social sciences, with greater confidence about the possibility of identifying system boundaries, thresholds and crisis points [11]. In cities and similar systems, these are probabilities or tendencies rather than foregone conclusions. Within the social world it is much more difficult to understand and anticipate the way systems develop and change. The door often needs to be left open for human ingenuity, technology and collective determination to intervene and avert a looming disaster or shift the trajectory out of its difficulties. Civic society may do what is required to regenerate a degraded ecosystem or revitalize a local economy under threat. A crisis can galvanize exceptional public effort and support, at least temporarily.

Second, resilience is not a neutral attribute since it may have contrasting and contested implications, prompting questions about who benefits from resilience [11,12]. Some sectional interests may gain from the process of building resilience and others may lose. Although cities are shared spaces with common destinies to some extent, they are also places from which particular segments of the population may be excluded, whether deliberately or unintentionally, and through physical or financial means. Hence values associated with justice and fairness may loom large in strategies to promote urban resilience, both in terms of how decisions are made and how the burdens and benefits are distributed.

Different kinds of resilience may be required at different times in the history of a city. Should cities like New York restore the same subway system that was flooded after Sandy or should they redesign and improve aspects of it in the light of altered climatic conditions and the availability of superior technologies? A disaster can be a catalyst for radical reform by exposing the limitations of existing arrangements and questioning the wisdom of prevailing practices [13]. There are three main interpretations of resilience in the literature: engineering (bounce-back), multi-equilibria (bounce-forward) and socio-ecological (evolutionary). These are best thought of as different responses to external shocks and stresses. In the following section, we discuss the insights from each of them within the context of sustainable cities.

\section{What Kind of Resilience Is Required for Sustainable Cities?}

\subsection{Engineering Resilience}

This is by far the most common meaning of resilience in the popular discourse and in government policy. In practical applications, it is most widely used in disaster or risk management. The focus is on whether a city or other system can recover its population, infrastructure and institutions following a catastrophic event (for recent examples, see [14,15]). The question is how fast and efficiently the system returns to a steady state. The emphasis is on resisting disturbance and conserving what exists. 
In natural resource management this leads to an approach that tries to optimize and control the flow of resources [16].

Several examples of this can be found in the United Nations Office for Disaster Risk Reduction campaign to make cities resilient [17]. Participating cities are encouraged to be pro-active in allocating sufficient budget for disaster relief, mobilizing citizens, building capacity in emergency services and putting infrastructural measures in place to reduce risk.

The Austrian city of Leinz, situated in the Eastern Alps, is one of their model cities. Plagued over the centuries by recurrent devastating floods that have destroyed buildings, bridges and other infrastructure, the municipality developed a specialized department to deal jointly with environmental and disaster management. This department co-ordinates all the volunteer emergency services and maintains the ecological functions of the river. Water gauges and retention basin monitoring are linked to authorities. If critical levels are reached, authorities are alerted and a siren warns the public.

The concept of resilience has also been used by social scientists to describe the strength of communities in the face of adversity. Social resilience in an engineering sense is the ability of groups to deal with external pressures without affecting their stability and cohesion [18]. For example, it could mean being able to absorb rising immigration flows without provoking conflict and disorder. London and Amsterdam are often held up as examples of relatively tolerant, cohesive cities. Social resilience could also mean being able to adapt systems (multi-equilibria resilience). In Fortaleza-Cearà Brazil, a slum community started their own bank to fund urban agriculture and other community needs when they could not access established bank finance [19].

Engineering resilience can be linked to the use of equilibrium in mainstream economics. A shock or disturbance may move an economy off its stable state-perhaps into recession and higher unemployment—while self-correcting market forces should in theory bring it back [20]. The resilience of different economies is assessed by their susceptibility to being diverted from their established paths and their response times to recover to a position where labor and other resources are more or less fully employed. One implication of this perspective is that resilient economies do not change their basic structure or function over time. The emphasis in this notion of resilience is on maintaining stability and the persistence of core functions.

Various mechanisms are built into the economy to ensure that the system is not thrown off balance [21]. The role of prices in regulating changes in the demand and supply of resources is an obvious example. Cities consist of all kinds of markets - for labor, land, housing and other types of property - in which these market interactions are commonplace. Yet, urban economies can still be forced off their established trajectory by many external factors. It could be pressures of intensified global competition, changes in consumer taste or demand for local products, or technological breakthroughs achieved by rivals. How cities respond depends on accumulated strengths in their institutions, infrastructure and other assets. Their economies may return to their previous position through some adjustment in wages, property prices or a more creative response, thereby demonstrating bounce-back resilience, or they could fail to cope effectively and stagnate or enter an era of decline.

In New York, it took about a week after Sandy for the electricity to be restored and the main subway lines to be operational. This called for an engineering approach to resilience, based on stability within the core infrastructure networks for the basic metabolism of the city to work. Without these essential services up and running, large parts of the economy could not have functioned, resulting in a 
loss of output and income. In a robust and resourceful urban economy, this type of resilience is possible and desirable in many respects, as the city operates relatively efficiently in the first place. Of course there may be other features of the city associated with social inequality and environmental degradation that are far less satisfactory.

Applying engineering resilience to places like Juba where most of the city lacks basic infrastructure and other formal systems of social, economic and environmental protection would not be very meaningful. There is effectively no established economy outside the government sector and rising levels of unemployment and poverty. Applying engineering resilience within this context would not offer a great deal. Instead, there is a strong case for some form of transformation and development to improve conditions all round, without degrading the natural ecosystems or informal social systems on which the city also depends.

In every city there are bound to be some parts of the fixed infrastructure or established institutions that do not warrant a return to the status quo and are not worth preserving. If it is feasible and affordable, change may be better than sustaining or coping with unsatisfactory systems. In New York, smart-grid technology would enable outages to be identified, isolated and repaired more quickly, and buried cables would be less exposed during storms. Similarly, with rising sea levels and more frequent and severe storms, steps might be taken to reconfigure parts of the shoreline or install sea barriers to reduce flooding. The alteration or transformation of existing systems and practices has given rise to other interpretations of resilience.

\subsection{Multi-Equilibria Resilience}

This concept of resilience emerged within ecology out of a recognition that disturbed systems did not always return to the same steady state. While many features might look similar, it was a somewhat different system or regime that re-emerged after a shock [16]. Accordingly, the possibility of more than one outcome or state of equilibrium is accepted. Unlike engineering resilience, multi-equilibria resilience regards systems as composed of many equilibria and able to shift from one regime to another. The transition to a different outcome depends on the system being disrupted by reaching a critical threshold.

Whereas engineering resilience focuses on the efficiency with which a system can recover, multi-equilibria resilience focuses on the robustness of the system, i.e. how long it can remain in a particular state and withstand change before reaching a tipping point and moving to a new regime. While the idea of a single equilibrium is rejected, it remains similar to engineering resilience in that its key feature remains stability rather than progressive change [11]. While this understanding of multiple equilibria was initially resisted by some ecologists, it is now widely accepted [16].

Adaptation is a core feature of an equilibrium approach to resilience. Unlike engineering resilience that seeks to restore a system affected by change, multi-equilibria resilience seeks to adapt the system to better cope or eliminate the stress or shock at hand. Various kinds of socio-ecological adaptations are engineered within cities to prevent pollution levels from tipping critical life-sustaining environmental limits or creating unhealthy dependencies. In Lagos, Nigeria, the government developed a bus rapid transit (BRT) system to reduce congestion and air pollution [22]. This helped to reduce carbon dioxide emissions by 13 per cent and travelling time for passengers, making the city more 
livable. In Singapore, to avoid dependency on piped water from Malaysia, the city constructed reservoirs for rainwater, developed water treatment plants to re-use water and repaired existing leaks to adapt to reduce water consumption.

A multi-equilibria perspective on resilient cities is also optimistic in envisaging alternative stable positions that can rectify some of the stresses under a current regime. Pendall [7] uses the example of Hurricane Katrina, which left hospitals, transportation systems and neighborhoods in disarray in New Orleans. Yet, it also exposed the pre-disaster situation as an unacceptable target for recovery. People did not want to return to the pre-existing situation characterized by overcrowding and inequality in services. There was compelling pressure for a new improved regime.

The prospect of alternative equilibria within an economy also raises the possibility that it may not be functioning optimally. Markets tend to be driven by self-interest and short-term considerations rather than the long-term horizons inherent in sustainability thinking. This became all too apparent with the global financial crisis, when concerns about the present completely obscured the future. For similar reasons, city planners generally struggle to get property developers and investors to take a longer-term and broader view of the neighborhoods, retail parks and business precincts they create. Consequently, the objectives of quality, livability, distinctiveness, public transport accessibility and resource efficiency get relegated below immediate commercial imperatives [20]. The outcome is often poorly-designed and badly-integrated developments with detrimental environmental and social effects.

A rather different illustration of the problem of convenient compromises relates to the close relationships that often exist between city governments and the providers of key utilities. These are a source of stability, but tend to prevent new suppliers from entering expanding markets for energy, telecommunications, water and waste collection. This often inhibits the introduction of newer, cleaner and more cost-effective technologies, thereby inflating the economy's cost base and restricting employment creation. A more open and enlightened approach might help to shift conditions towards a more advantageous economic and environmental position.

The idea of multiple equilibria captures the shifting composition of city economies as a result of wider competitive forces and developments in technology. Cities have always had to adjust or adapt their structures to changing conditions and 're-invent' their purpose and identity in the face of shifts in the economic environment or the loss of comparative advantage they previously enjoyed [20,23]. De-industrialization has been a particular challenge to the first generation of large cities that emerged with the growth of manufacturing. It has required the development of new knowledge-based, creative and service industries, the reorientation of local educational institutions and the reshaping of property markets [24]. Cities founded upon single natural resources or specialized industries have often faced the biggest difficulties of diversification and repositioning.

Nairobi (Kenya) is an example of a city in the process of recovering from deindustrialization induced by structural adjustment policies through developing new markets and new technologies. Key parts of government and the private sector are actively pursuing the economic potential of mobile phones and related financial services with the vision of the city becoming a technology and innovation hub [25]. Substantial investment by the Kenyan government in undersea internet cables has been instrumental in boosting bandwidth and cutting prices of internet access. Innovation in cashless payment systems has also stimulated many new businesses engaged in developing all sorts of mobile applications. The start-up and growth of telecoms-based enterprises has been reinforced by increasing 
amounts of domestic and international investment in business incubators. Major global companies such as Google, Nokia, Microsoft, IBM, Hewlett Packard and France Telecom have demonstrated their confidence in the city's future by taking stakes in local companies, support services and infrastructure.

One advantage of a multi-equilibria approach to the urban economy is that it keeps in play both stability and innovation through adaptation. A degree of continuity may be important to protect core assets, institutions and livelihoods while new opportunities are developed and the transition to new forms of production occurs. Stability gives organizations and individuals time to adapt and develop new functions, systems and skill-sets, although unwarranted protection may of course inhibit entrepreneurship and adaptation by relieving the pressure to change. There are difficult balances involved, which will vary depending on the context and the collective choices that are made.

Some evolutionary economists [23] are skeptical of a multi-equilibria framework for analyzing the economy. They acknowledge that ecological systems may attain stable states if left undisturbed, but economic systems are considered different. Economic evolution depends on the actions of individual agents who can experiment, learn and change their behavior. While economies may exhibit stability and self-organization, they are essentially about ongoing adjustment to new and emerging conditions, especially in the face of intensified international competition. This shifts the focus from a desire to stabilize conditions to an imperative to support continuous adaptation through rising productivity and innovation over time.

\subsection{Socio-Ecological Resilience}

This notion of resilience focuses on the dynamic interaction between social and ecological change [23]. The human and biophysical systems are seen as linked and co-evolving rather than independent. This differs from the previous perspectives that focus on recovery to a state where economic, social and environmental relationships are stable, or shift to a new stable domain. Communities and cities are complex human systems that interact with a variety of natural systems operating at different levels [12]. These interactions occur across multiple scales, creating a situation in a state of great flux. A simple example is the dependence of contemporary urban populations on food produced in many different rural ecosystems, some of which are within the same region and others in different countries and continents. An incidental benefit of having diverse suppliers and back-up systems ('spare capacity') is enabling the core function of food security in the city to be maintained if one of its suppliers fails.

The key features of complex adaptive systems are described by Cilliers [26] as having many elements that interact dynamically with each other, creating direct and indirect feedback loops. The behavior of the system is better explained by the nature of the interactions than by a focus on the components of the system alone. The concept of 'emergence' is used to describe how surprising patterns arise out of many relatively simple interactions and their ripple effects. Emergence does not disregard causality, but it argues against linear relationships and deterministic prediction. Feedback loops and reinforcing mechanisms make it difficult to forecast the evolving behavior of complex systems, even with full information [20]. Such systems also have self-organizing capabilities, which give them strength and the ability to transform in the face of internal and external threats. 
The socio-ecological notion of resilience treats it as a process rather than the description of an outcome [7]. The focus is not a state of equilibrium but a state of continual adjustment and evolution. This gives rise to the metaphor of the adaptive cycle. This has four distinct phases in the structure and function of a system: growth or exploitation ( $\mathrm{r}$ ), conservation or consolidation $(\mathrm{K})$, release or creative destruction $(\Omega)$ and renewal or reorganization $(\alpha)$ [27]. In the first phase, resources and assets are developed and the system stabilizes. Then a slower conservation phase occurs where the system becomes more predictable and brittle. This opens up new and uncertain possibilities, implying that as systems mature they become less resilient and more fragile. Consequently, this is followed by systemic breakdown when resources are released, and then a new phase of reorganization and regeneration occurs. This implies that crises are times of innovation and transformation, when problems can be turned into opportunities, with foresight and preparation. It is not a fixed cycle since the system can move through different sequences.

The rise and fall of adaptive cycles in the public and private sectors is well illustrated in the city of Detroit. Major car manufacturers seem to have experienced something of a comeback after a difficult period, and are re-investing in the city [28]. Their resurgence has been matched by a range of out of town investors and young entrepreneurs taking advantage of low property prices within the city. Meanwhile, a financial crisis in local government has forced the municipality to look to the federal state for assistance. In essence, the slump appears to have opened up opportunities for newcomers, social activists and entrepreneurs.

Holling [29] identifies three central properties of the adaptive cycle that shape the responses of people, ecosystems and agencies to threats and crises: the inherent potential of the system, the internal connectedness between the variables, and the adaptive capacity or resilience of the system. As the phases of the adaptive cycle progress, resilience contracts and then increases. In the disintegration phase the system is not strongly connected, so it is considered reasonably resilient. Creativity and experimentation occur because the costs of system failure are low. The variability of resilience within the adaptive cycle allows for periods of relative stability, flexibility and creative dynamism.

Recent research on London and other leading European cities has demonstrated the economic value and strength derived from dense local networks of business suppliers and services [30,31]. In a context of fast-changing markets and technologies, there is a premium on flexibility, especially as leading companies tend to be leaner and more reliant on buying-in goods and services rather than in-house production. The diversity of big cities enables firms to 'mix and match' their inputs and alter their workforce more easily in response to shifting business needs. This self-organizing, dynamic property of these places lowers costs, raises productivity and improves adaptation. Knowledge-intensive firms also benefit from superior flows of ideas and information, resulting in more learning and innovation. This enables high cost cities to differentiate themselves from competitors by continually developing more valuable products, processes and services [24]. Firms can compare, compete and cooperate, engendering a self-reinforcing dynamic that spurs progress, attracts mobile capital and talent, and generates growth from within. The most successful cities operate as knowledge hubs or gateways in a more interconnected global system of information, trade and financial flows [32].

Panarchy describes the multi-scalar nature of socio-ecological systems as they develop, disintegrate and re-emerge in response to changing conditions in different levels. The interactions between levels occur in both directions. The strength of these influences varies at different phases of the adaptive 
cycle. This general framework allows one to conceptualize how disruptions to systems can occur from external forces as well as internal sub-system pressures. Resilience depends on the complex interplay of these different systems, each of which under-go their own dynamic adjustment processes. This perspective helps to avoid examining individual urban areas in isolation. Cities need to be understood as dynamic systems comprised of smaller sub-systems and forming part of larger national and international systems, all of which affect their resilience capabilities [33,34].

A regional comparative study of long-term economic change in Cambridge and Swansea in the UK demonstrated how different choices and partnerships made within each city affected their levels of resilience through two recessions [20]. To boost their economy, Swansea focused on attracting foreign direct investment (manufacturing Japanese electronic products), and thereby relied on exogenous knowledge. Cambridge, on other hand, chose to invest in endogenous knowledge and build a science park, combining this with market-driven entrepreneurship and commercial exploitation of university intellectual property rights. Swansea emerged far less successfully, because their technologies became outdated and the multi-national companies did not develop local capabilities to anything like the same extent.

Swanstrom [23] draws parallels between cities and ecosystems in describing how they have extensive feedback loops that operate on multiple dimensions of time and place. In order to respond effectively to the pervasive pressures of traffic congestion, immigration and environmental degradation, cities need to be viewed as complex adaptive systems. This helps to caution against narrow, insular policy interventions that may produce unintended consequences for other parts of the system. For example, cities that seek to alleviate poverty by subsiding the travel costs of poor communities living on the periphery may inadvertently perpetuate fragmented spatial development patterns and prolong inefficient transport and bulk infrastructure arrangements, rather than encourage a more compact and integrated urban form [35].

Two additional terms can be introduced to explain the types of change that are considered essential for social-ecological resilience: adaptability and transformability [8,29]. Adaptability focuses on the ability of the socio-ecological system to adjust to external and internal change through self-organization and collective learning. Transformability is the capacity to progress to a new arrangement when the current situation is untenable and unsustainable. Socio-ecological resilience tends to place greater emphasis on the latter, i.e. systemic change to avoid getting locked-in to inappropriate structures.

\section{Shifting the Emphasis in Resilience Thinking}

All three interpretations of resilience offer valuable insights for the development of sustainable cities. Their contributions recognize different features and time-scales, respond to different kinds of shocks, and exhibit varying levels of moral deliberation. Engineering resilience draws attention to the importance of short-term stability in essential urban infrastructure when extreme events like earthquakes or hurricanes occur. The moral deliberation that occurs tends to focus on those most at risk, who should receive priority attention. Because of its emphasis on efficiency in returning to a previous equilibrium and retaining the basic structure and ways of functioning, bounce-back resilience tends to leave little room for reflection on whether this position is still appropriate and desirable. 
Multi-equilibria resilience has a longer-term perspective, which allows for more consideration of alternative futures. It identifies critical thresholds within the system, which warn about approaching limits to stability. The notion of multiple equilibria encourages consideration of different outcomes so as to improve conditions for current communities. Yet the focus on stable states plays down the significance of ongoing adjustment and flexibility to accommodate unforeseen pressures and crises.

Socio-ecological resilience represents a broader interpretation of resilience for more complicated, interdependent systems open to all kinds of stresses and severe events. It represents the most extended form of moral deliberation because it attempts to develop capacity within the economy, society and ecology to cope with many different factors and forces. Systems need to allow for continual adaptation to changing circumstances and inherent instability. Coping with the uncertainty, unpredictability and risks associated with such a state of flux is particularly difficult for political decision-makers.

While these notions of resilience offer a range of options to deal with change (recovery, adaptation and transformation), a sharper focus on the human capabilities as well as the technological aspects of change would further strengthen its analytical power. This can be achieved by drawing on the insights of vulnerability theory and transition theory more strongly. The following section provides further insights from this perspective.

\section{Developing the Human Face of a Resilient City}

Resilience and vulnerability are two different, yet related, ways of framing responses to social-ecological change [36]. Exactly how they relate is contested. Some view vulnerability as the opposite of resilience, while others see vulnerability as a component of resilience. It is an oversimplification to treat resilience as the converse of vulnerability because they refer to slightly different features [37]. Resilience is the responsiveness of the system, i.e. its elasticity or capacity to rebound after a shock, indicated by the degree of flexibility, persistence of key functions, or ability to transform. Vulnerability is more about the susceptibility of the system or any of its constituents to harmful external pressures.

The scope of both frameworks also tends to differ, partly because they have different origins and research traditions. Resilience emerged from ecology, whereas vulnerability emerged from political ecology, political economy and disaster risk approaches [36]. Traditionally resilience has tended to emphasize the ultimate impact on biophysical ecosystems, whereas vulnerability was oriented towards human systems and social outcomes [36,38,39]. Vulnerability theory has traditionally paid more attention to the values and agency of stakeholders along with issues of socio-historical change, identifying who is responsible for supporting marginalized people and places so they are not left behind. Resilience has focused on system dynamics and interconnections, ecological thresholds and feedback loops. In the past, it addressed the human dimension largely in the context of managing resources and ecosystem services [36]. However, as resilience theory has become used more frequently in the social sciences, questions about the resilience of what and for whom have become more central to the debate [40]. These issues determine what desirable functions of ecosystems are given priority in what areas of need. Previously the domain of vulnerability theory, the plight of marginal and disenfranchised groups is now part of resilience analysis. 
In the past, resilience thinking has been criticized for not questioning the social and economic systems that cause inequality and marginalize communities enough [23,41,42]. This criticism is perhaps still justified in the case of engineering resilience because of its emphasis on preserving the status quo. It is not so valid, however, with other interpretations of resilience, which offer greater scope to consider alternative social realities and outcomes. Resilience theory may also have been conservative in concentrating on how existing social systems can absorb change and retain their essential structure and functions, rather than how they can be reformed or transformed $[12,43]$.

The body of literature on vulnerability has engaged with these kinds of issues more extensively than the resilience literature [37]. This may be attributable to the more diverse disciplines that have influenced vulnerability thinking, including political ecology and political economy. Some concern has been expressed that the resilience framework applied to social systems neglects the man-made character of the laws and other institutions governing society. Established rules and frameworks tend to be taken for granted without questioning their rationale and validity [44]. An unintended effect may be to sanction the persistence of social injustice or environmental harm, or at least to play down the possibility of substantive change.

These kinds of concerns are starting to be raised in the resilience literature. Moore and Westley [45] discuss the importance of networks and social innovation for resilient systems. They argue that institutional entrepreneurs with specific skill-sets can be key agents in bringing about change. By establishing the right kinds of relationships that expand their networks at the right time, they can bridge divides and affect change at a larger scale.

In summary, insights from vulnerability thinking can complement resilience perspectives by drawing greater attention to human systems, social outcomes and the role of political decision-making. They remind researchers to avoid an uncritical acceptance of the underlying assumptions about the society and its structures of political and economic power. The next section considers the insights from transition theory.

\section{Introducing Technological Change}

The primary focus of resilience on socio-ecological systems has tended to relegate technology to an external factor [46]. There is a case for incorporating technological change more directly into resilience thinking because of its role in enabling change and building resilience capabilities. While social processes shape the development of technology and its absorption by households and firms, technologies also create the possibility for new social and environmental practices. Indeed technology of one sort or another is vital to the interactions within almost all socio-ecological systems and exerts a major influence on their outcomes. Technology can help to re-engineer cities so as to reduce their ecological burden and impact on natural resource consumption by making more efficient use of scarce resources, enhancing local capacity to produce food and energy, and reducing the amount of waste they generate through recycling.

This lies behind the growing interest in the notion of 'green urbanism', or a new paradigm for building more sustainable cities [47,48]. The vision goes beyond piecemeal environmental initiatives to suggest a perspective of cities as more self-contained systems in which a higher proportion of food, building materials, energy and other resources consumed are procured locally. One element would 
include clean production technologies and transport systems, which use fossil fuel energy resources more efficiently and generate lower carbon emissions than older methods. Another would be new techniques of energy conservation and green building to save running costs for firms and households, and create jobs from construction and retrofitting. A third ingredient would be improved systems of environmental protection and waste management to restore degraded ecosystems and support enhanced livelihoods for poor communities. Closing resource loops means shifting from a linear to a circular urban metabolism, where waste flows are redefined as productive inputs to other urban activities. A green agenda of this kind could create all sorts of opportunities to establish stronger local economies, healthier lifestyles and more livable places with smaller ecological footprints.

Transition theory uses a multi-level framework to analyze the interaction between technological and social change $[49,50]$. This helps to explain how technical innovation influences socio-ecological processes. It analyses transitions through three hierarchical structures: niches, regimes and landscapes [51]. A regime is the institutional and infrastructural arrangement within which a particular technological system functions. It emerges through the everyday interactions between actors and institutions and is embodied in a wide-ranging set of engineering practices, production processes, institutional procedures and skill-sets. Changes at regime level tend to be incremental without radically altering traditional practices and production systems.

The landscape is the level above this, encapsulating the broader political, social and cultural structures that form part of the bedrock of society. They are highly resistant to change and may block developments that threaten established interests and power relations. Niches represent the diverse spaces within regimes that have some protection from prevailing institutional practices, market forces, social norms and/or regulatory standards. These spaces facilitate social experimentation and technological innovation because some of the restrictive conditions that exist in the rest of the regime are relaxed or do not apply.

Masdar City may be an example of an attempt to foster niche innovation in a landscape of diminishing fossil fuels and global warming. It is being planned by the oil-rich state of United Arab Emirates (UAE) as an "eco-city" experiment in Abu Dhabi [52]. Masdar City is designed to accommodate 40,000 residents and 50,000 daily commuters in carbon neutral, zero waste conditions. The project is intended to pilot and develop the full range of specialized skills, innovative building techniques, renewable energy systems and infrastructure networks to realize the eco-city concept. An Institute of Science and Technology has been established in collaboration with MIT in the US to facilitate the two-way transfer of knowledge and expertise between the niche of Masdar City, the wider context of the UAE and other parts of the world.

Transition theory adds a further dimension to resilience in that it transcends the physical setting of a socio-ecological system. It recognizes that technological change may occur across multiple locations through organized and spontaneous flows of information and expanding communication networks [46]. In other words, the diffusion of technology across and between systems can be an important part of transformation. Access to creativity and innovation occurring in other cities and nations extends the options available for local regeneration and restructuring. This depends on the relevance of the technology designed elsewhere to the local context and the existence of sufficient institutional capacity and resources to absorb the lessons learnt [53]. 
An important aspect of keeping an urban economy vibrant is being receptive to new technological innovation elsewhere and finding ways of attracting and also developing these skills within the city [54]. One of the ways of achieving this is by developing innovation systems within local institutional structures that are focused both on the vulnerabilities within an urban area as well as the possible solutions for these problems found elsewhere. Attempts to achieve this in the past have included the establishment of science parks, technology incubators and living laboratories.

Summing up, transition theory extends resilience thinking by incorporating technological change more directly into the analysis of socio-ecological systems. This also implies paying greater attention to the connectivity between cities and other systems, including the flows of information, knowledge and finance. These flows can perform a positive and progressive function, or they can expose cities to greater risks and instability.

\section{Expanding the Analytical Framework for Resilience Research}

Recent reports on developing resilience in cities have largely focused on disaster and risk management $[14,15]$. Their analytical framework, though open to concept of adaptation, is mostly limited to shorter-term resilience in the face of natural disasters like flooding and drought. They analyze, for example, the specific resilience of the existing infrastructure in a city to natural disasters, as opposed to the general resilience of its infrastructure towards longer term issues of transformation. The importance of specific or bounce-back resilience is undisputed as there is a need to ensure that vital facilities like power plants, water and sanitation systems and hospitals resume functioning as soon as possible following a disaster. Without this kind of first-order resilience, a society and its supporting economy can readily be brought to its knees.

This paper attempts to broaden the concept of resilience by expanding the analytic framework for understanding sustainable cities. In addition to examining engineering resilience it discusses two other kinds of resilience related to the long-term sustainability of cities as dynamic social organizations: multi-equilibria resilience and socio-ecological resilience. We also introduce two other aspects of resilience: human vulnerability and innovation which though discussed within the literature, are not emphasized as much as they are in the vulnerability and transition theory analyses. The diagram (Figure 1) below serves as an illustration of the discussion that follows on the different the types of resilience and their relationship to vulnerability studies and social or technological innovation.

Figure 1. Dimensions of a resilient city.

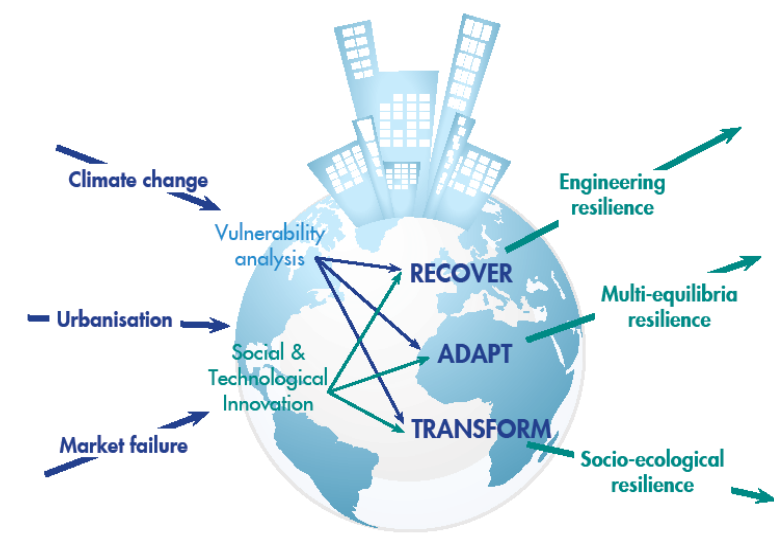


Multi-equilibria resilience emphasizes the importance of paying attention to tipping points or thresholds within social, economic and ecological systems to avert disaster. This second dimension of resilience could be referred to as preventative and adaptive resilience where warning signs in social, economic and ecological environments are monitored so that interventions can be planned before crises arise and the entire socio-economic and ecological system is weakened or seriously damaged. Research focusing on this type is already found in attempts to measure resilience in city economies by producing ecological and economic indicators to benchmark levels of water purity, air pollution, unemployment, crime and education. These indicators are used to monitor critical levels to enable adaptation or intervention before serious damage occurs.

Socio-ecological resilience is a third dimension that looks beyond such indicators at the dynamic interchange between the social and ecological factors in an economy and their simultaneous interaction with these same forces both beyond the city borders and within various precincts within the city. It speaks about a more general form of resilience that is aimed at long term stability and flexibility. In this third dimension, what are being gauged are essentially the deep underlying forces driving change both within the economic system and outside it. The focus is on understanding the kind of long-term forces at play rather than attempting to predict particular outcomes in the short term. The value of a more general resilience analysis lies in understanding long-term adaptive capacity to cope with constant change.

This paper calls for two additional areas of background analysis in resilience theory, one aimed at identifying and supporting processes of social innovation in vulnerable communities, and the other at identifying processes of technological innovation. In order to achieve a better understanding of the former, resilience analyses are likely to benefit greatly from incorporating the insights of vulnerability studies. Understanding the particular challenges and capabilities of the people most affected by change is likely to improve their ability to adapt or transform it. If resilience analyses incorporate vulnerability insights, they would be better equipped to identify processes of social progress within these communities and support the social entrepreneurs who are trying to bring about institutional change. Secondly, identifying and supporting processes of technological innovation would also extend resilience. While resilience theory makes explicit reference to transformation within socio-ecological resilience, the focus remains socio-ecological cycles rather than socio-technical cycles. Socio-ecological interactions are physically located, whereas socio-technical systems have both local and global bearings. If resilience theory were to incorporate the insights of transition theory in their analyses of change within socio-ecological systems, they would strengthen their analytical capabilities. The core focus at this level of resilience analysis is an understanding of how an urban area nurtures and attracts technological innovation. It demands an assessment of relationships between government, economic and social agents with many practical implications.

It is proposed that these three dimensions of resilience and two background analyses are critical for identifying the core features of building sustainable cities. These core features are summarized as: the ability to recover, to adapt to new equilibria, to transform when necessary and to facilitate social and technologically innovative processes. How this can be achieved within a particular city and its unique social and ecological adaptive cycles would need to be researched within each particular context. 


\section{Conclusions}

The paper has reviewed several different theoretical frameworks for understanding the essential features of sustainable cities - resilience, vulnerability and transitions. The broad perspective of resilience provides a range of insights into how major urban areas deal with external challenges and shocks to the way they manage their assets and resources. The fundamental point is that for the simplest objectives of survival and growth, cities need to be able to avoid hazardous conditions where possible or respond positively where risks are unavoidable and change is inevitable.

In some circumstances they need above-all to withstand disasters and bounce back from adverse stress (engineering resilience). Retaining essential urban functions is important to avoid systemic crises and breakdown. In other situations it is vital that cities adapt to a new environment by adjusting certain structures and systems to match the altered conditions (multi-equilibria resilience). They may be experiencing stagnation or have reached a critical threshold beyond which incremental change is necessary to regain a steady state. In a third, highly dynamic situation, a process of ongoing change occurs as cities continually rearrange their structures and reorganize their institutions (socio-ecological resilience). It is important for them to avoid becoming locked into a single development path based on outdated arrangements and inappropriate patterns of resource use.

Resilience thinking initially tended to neglect how socio-ecological change affected a particular community. Engineering approaches to resilience especially tend to play down the diverse interests within cities and the need to disentangle the ultimate objectives of sustainability and resilience-for whom and for what? Theories of vulnerability can complement resilience by elevating the importance of human systems and social outcomes. They caution against an uncritical acceptance of the underlying power relations, and encourage more explicit consideration of the role of political decision-making. Transition theories focus on the relationship between social and technological change. They can help resilience research to guard against inertia and point to the importance of knowledge and information flows between different cities, nationally and internationally.

Previous research has tended to portray these theoretical frameworks as alternatives. Researchers and writers have typically advocated one perspective over another, and have generally applied them in isolation. The present paper has suggested that their insights could be complementary and mutually supportive. For resilience analyses to identify and support process of social innovation within communities, they are likely to need to understand the vulnerabilities and social dynamics that exist in these places. Vulnerability studies can provide this background. Similarly, if resilience analyses are to effectively identify and support processes of technological innovation in a city, an understanding of how these processes function is vital.

This paper advocates a resilience approach to building sustainable cities. This is because the multiple interpretations of resilience provide diverse insights into the broad attributes required to prepare a city for short and long term change. The paper suggests that resilience theory could improve its analyses of social and technological innovation by adopting some of the insights of vulnerability and transition theory.

The issue of when to apply a particular kind of resilience in a city depends entirely on the natural and human resources available in that place. In some circumstances the key attribute of a resilient city is its ability to recover quickly from a shock. In other circumstances cities need to adjust to new 
conditions because their established structures or systems are no longer fit for purpose. This process of change may be ongoing if the environment is continually shifting and it is not feasible or viable for cities to stand still.

Each type of resilience may have a somewhat different time-frame. Coping may be the most appropriate short-term response to a disaster, while adaptation is likely to be important in the longer-term. Each may also apply more to one feature of the city than to another - its physical infrastructure, public services, leading economic sectors, or governing institutions. Some aspects may require one-off or incremental adaptation, while others require continuing adjustment or enhancement. These differences may also vary for cities at different stages of development or located in different territories, so that some require all-round improvement while others need modest modification. Determining which perspective is most appropriate in what circumstances is neither simple nor straightforward.

It is the task of resilience researchers to balance and prioritize the different attributes discussed in this paper when attempting to map out resilience strategies for cities. While there may be tensions and contradictions between the different perspectives that cannot be neatly reconciled in practice, cities that are capable of maintaining stable, yet flexible and innovative systems stand the best chances of developing sustainably.

\section{Conflict of Interest}

The authors declare no conflict of interest.

\section{References}

1. United Nations Department of Economic and Social Affairs Population Division. World Urbanisation Prospects; United Nations: New York, NY, USA, 2012.

2. Grant, R.; Thompson, D. The development complex, rural economy and urban-spatial and economic development in Juba, South Sudan. Local Econ. 2013, 28, 77-88.

3. Holling, C.S. Resilience and stability of ecological systems. Annu. Rev. Ecol. Syst. 1973, 4, 1-23.

4. Brand, F.S.; Jax, K. Focusing the meaning(s) of resilience: Resilience as a descriptive concept and a boundary object. Ecol. Soc. 2007, 12, 23:1-23:16.

5. Carpenter, S.; Walker, B.; Anderies, J.M.; Abel, N. From metaphor to measurement: Resilience of what to what? Ecosystems 2001, 4, 765-781.

6. Christopherson, S.; Michie, J.; Tyler, P. Regional resilience: Theoretical and empirical perspectives. Camb. J. Reg. Econ. Soc. 2010, 3, 3-10.

7. Pendall, R.; Foster, K.A.; Cowell, M. Resilience and regions: Building understanding of the metaphor. Camb. J. Reg. Econ. Soc. 2010, 3, 71-84.

8. Folke, C.; Carpenter, S.R.; Walker, B.; Scheffer, M.; Chapin, T.; Rockström, J. Resilience thinking: Integrating resilience, adaptability and transformability. Ecol. Soc. 2010, 15, 1-9.

9. Carpenter, S.R.; Arrow, K.J.; Barrett, S.; Biggs, R.; Brock, W.A.; Crépin, A.S.; Engström, G.; Folke, C.; Hughes, T.P.; Kautsky, N.; et al. General resilience to cope with extreme events. Sustainability 2012, 4, 3248-3259.

10. Evans, J.P. Resilience, ecology and adaptation in the experimental city. T.I. Brit. Geogr. 2011, 36, 223-237.

11. Davoudi, S. Resilience: A bridging concept or a dead end? Plann. Theor. Pract. 2012, 13, 299-307. 
12. Cote, M.; Nightingale, A.J. Resilience thinking meets social theory: Situating social change in socio-ecological systems (ses) research. Prog. Hum. Geog. 2012, 36, 475-489.

13. Pelling, M. Adaptation to Climate Change: From Resilience to Transformation; Routledge: London, UK, 2011.

14. United Nations Office for Disaster Risk Reduction (UNISDR). Making Cities Resilient Report; UNISDR: New York, NY, USA, 2012.

15. Godrey, N.; Savage, R. Future Proofing Cities: Risks and Opportunities for Inclusive Urban Growth in Developing Countries; Atkins: Epsom, UK, 2012; p. 188.

16. Folke, C. Resilience: The emergence of a perspective for social-ecological systems analyses. Global Environ. Change 2006, 16, 253-267.

17. United Nations Disaster Risk Making Cities Resilient Campaign. Available online: http://www.unisdr.org/campaign/resilientcities/cities/view/2764/ (accessed on 10 April 2013)

18. Adger, W.N. Social and ecological resilience: Are they related? Prog. Hum. Geog. 2000, 24, 347-364.

19. Noya, A.; Clarence, E. Community capacity building: Fostering economic and social resilience. Organisation for economic cooperation and development, 26-27 November 2009. Available online: http://www.oecd.org/dataoecd/54/10/44681969.pdf?contentId=44681 970 (accessed on 10 April 2013).

20. Simmie, J.; Martin, R. The economic resilience of regions: Towards an evolutionary approach. Camb. J. Reg. Econ. Soc. 2010, 3, 27-43.

21. Adams, D.; Tiesdell, S. Shipping Places: Urban Planning, Design and Development; Routledge: London, UK, 2012.

22. Robinson, B.M. Optimizing infrastructure: Urban patterns for a green economy; UN Habitat: Nairobi, Kenya, 2012.

23. Swanstrom, T. Regional Resilience: A Critical Examination of the Ecological Framework; Working Paper 2008-7; Institute of Urban Regional Development, University of California: Oakland, CA, USA, 2008.

24. Turok, I. The distinctive city: Pitfalls in the pursuit of differential advantage. Environ. Plann. A 2009, 41, 13-30.

25. The Economist. Upwardly mobile: Kenya's technology start-up scene is about to take off, 2012. Available online: http://www.economist.com/node/21560912 (accessed on 18 November 2012).

26. Cilliers, P. What can we learn from a theory of complexity? Emergence 2000, 2, 23-33.

27. Walker, B.; Holling, C.S.; Carpenter, S.R.; Kinzig, A. Resilience, adaptability and transformability in social-ecological systems. Ecol. Soc. 2004, 9, 5.

28. Davey, M. A private boom amid Detroit's public blight. New York Times, 4 March 2013. Available online: http:/www.nytimes.com/2013/03/05/us/a-private-boom-amid-detroits-publicblight.html?pagewanted=all/ (accessed on 10 April 2013).

29. Holling, C.S. Understanding the complexity of economic, ecological, and social systems. Ecosystems 2001, 4, 390-405.

30. Buck, N.; Gordon, I.; Harding, A.; Turok, I. Changing Cities: Rethinking Urban Competitiveness, Cohesion and Governance; Palgrave: London, UK, 2005.

31. Hall, P.; Pain, K. The Polycentric Metropolis; Earthscan: London, UK, 2006. 
32. Castells, M. The Information Age: Economy, Society and Culture. Volume 1: The Rise of the Network Society, 2nd ed.; Blackwell: Oxford, UK, 2000.

33. Lucci, P.; Hildreth, P. City Links: Integration and Isolation; Centre for Cities: London, UK, 2008.

34. Turok, I. Cities, Regions and competitiveness. Reg. Stud. 2004, 38, 1069-1083.

35. Behrens, R.; Wilkinson, P. Housing and urban passenger transport policy and planning in South African cities: A problematic relationship? In Confronting Fragmentation: Housing and Urban Development in a Democratising Society; Harrison, P., Huchzermeyer, M., Mayekiso, M., Eds.; Cape Town University Press: Cape Town, South Africa, 2003; pp. 154-174.

36. Miller, F.H.; Osbahr, E.; Boyd, F.; Thomalla, S.; Bharwani, G.; Ziervogel, B.; Walker, J.; Birkmann, S.; van der Leeuw, S.; Rockström, J. Resilience and vulnerability: Complementary or conflicting concepts. Ecol. Soc. 2010, 15, 11.

37 Turner, B.L. Vulnerability and resilience: Coalescing or paralleling approaches for sustainability science? Global Environ. Change 2007, 20, 570-576.

38. Eakin, H.; Luers, A.L. Assessing the vulnerability of social-environmental systems. Annu. Rev. Environ. Resour. 2006, 31, 365-394.

39. Ernstson, H.; van der Leeuw, S.E.; Redman, C.L.; Meffert, D.J.; Davis, G.; Alfsen, C.; Elmqvist, T. Urban transitions: On urban resilience and human-dominated ecosystems. AMBIO 2010, 39, 531-545.

40. Porter, L.; Davoudi, S. A politics of resilience for planning: A cautionary note. Plann. Theor. Pract. 2012, 13, 329-333.

41. MacKinnon, D.; Derickson, K.D. From resilience to resourcefulness: A critique of resilience policy and activism. Prog. Hum. Geog. 2012, 37, 253-270.

42. Hassink, R. Regional resilience: A Promising concept to explain differences in regional economic adaptability? Camb. J. Reg. Econ. Soc. 2010, 3, 45-58.

43. Hudson, R. Resilient regions in an uncertain world: Wishful thinking or a practical reality? Camb. J. Reg. Econ. Soc. 2010, 3, 11-25.

44. Christmann, G.; Ibert, O.; Kilper, H.; Moss, T. Vulnerability and Resilience from a Socio-spatial Perspective. Towards a Theoretical Framework; Working Paper for Leibniz Institute for Regional Development and Structural Planning (IRS); No. 45; IRS: Leibniz, Germany, 2012; pp. 1-31.

45. Moore, M.; Westley, F. Surmountable chasms: Networks and social innovation for resilient systems. Ecol. Soc. 2011, 16, 5.

46. Smith, A.; Stirling, A. The politics of social-ecological resilience and sustainable socio-technical transitions. Ecol. Soc. 2010, 15, 11.

47. Beatley, T., Ed.; Green Cities of Europe; Island Press: Washington, DC, USA, 2012.

48. Swilling, M.; Annecke, E. Just Transitions: Explorations of Sustainability in an Unfair World; UCT Press: Cape Town, South Africa, 2012.

49. Haxeltine, A.; Seyfang, G. Transitions for the People: Theory and Practice of 'Transition' and 'Resilience' in the UK's Transition Movement; Tyndall Working Paper 134; University of East Anglia: Norwich, UK, 2009.

50. Van der Brugge, R.; van Raak, R. Facing the adaptive management challenge: Insights from transition management. Ecol. Soc. 2007, 12, 33. 
51. Foxon, T.J.; Reed, M.S.; Stringer, L.C. Governing long-term social-ecological change: What can the adaptive management and transition management approaches learn from each other? Environ. Pol. Govern. 2009, 19, 3-20.

52. Peter, C.; Swilling, M. Sustainable, Resource Efficient Cities-Making it Happen; DTI/1538/PA; UNEP Division of Technology Industry and Economics (DTIE): Paris, France, 2012.

53. Coyle, D. The Economics of Enough: How to Run the Economy as if the Future Matters; Princeton University Press: Princeton, NJ, USA, 2011.

54. Ridge, S.G.M. Innovation, innovation systems, science parks and living labs. Unpublished paper for the South African Department of Science and Technology, 2010.

(C) 2013 by the authors; licensee MDPI, Basel, Switzerland. This article is an open access article distributed under the terms and conditions of the Creative Commons Attribution license (http://creativecommons.org/licenses/by/3.0/). 